\title{
VISUAL ROUTES AND DIGITAL LIVES: \\ USING VISUAL ETHNOGRAPHY TO EXPLORE THE IMPORTANCE OF SOCIAL MEDIA AMONGST YOUNG BHUTANESE REFUGEE WOMEN
}

Jessica Halley ${ }^{1}$

\begin{abstract}
The interconnectedness of the internet and camera technology presents visual and digital researchers with a series of routes with which to navigate digital life. This research explores a series of still photos taken by four young Bhutanese refugee women, growing up in Palmerston North. What has been most striking are the photos they have taken of themselves, such photos are referred to as 'selfies'. These selfie photos are taken for purposes of sharing across digital social media networks. Following these routes transformed this research project from a visual ethnography into a visual and digital ethnography. This research highlights the ways in which social media photos provide textual examples of what is meaningful to particular youth cultures.
\end{abstract}

Keywords: visual ethnography; digital ethnography; social media; Bhutanese refugees; refugee women; youth culture

\section{INTRODUCTION}

\section{Visual Ethnography in a Digitalised Field}

Traditional methods of visual ethnography mine still photos for ethnographic data using two approaches. Most commonly, photos are embedded within ethnographic writing. Accompanied by text, they are referenced in the past tense, utilised as textual illustrations of the ethnographer's written word, and provide validity to the ethnographer's claims, proof that 'I was there' (Davis 1992, 209). Alternatively, visual ethnographers also utilise photographic techniques as methodological tools, whereby research participants engage in photography projects, or photographs are used as intellectual prompts during interviews (Allan 2005, 20; Becker 1974, 9; Bloustien and Baker 2003, 69; Schwartz 1989, 126; 
Trafi-Prats 2009, 11). These approaches to visual ethnography have developed through subject and audience understandings of photographic practices. Both Byers $(1964,82)$ and Sekula $(1975,39)$ found that American viewers approach photographs from two perspectives; as art forms, and as machine-generated records of particular subjects or scenes. Yet, camera-based technology has changed dramatically since 1975 , as have our photographic practices. The rise of digital technology has made photo taking an instant, infinite and low-cost practice. Cameras now travel with us, built into smartphone technology and connected to the internet, allowing photos to move freely across an array of digital communication networks.

This research explores a series of still photos taken by four young Bhutanese refugee women, growing up in Palmerston North. Over the course of my fieldwork I came to see how important photo taking was to these young women. Digital technologies make it possible for these young women to experiment with 'Western'2 codes of femininity in new ways, this process involves ever changing ways to style the body. Here, the girls use photography neither as an art form, nor a machine-generated record of a subject or scene, but as a way of knowing the world around them. As their offline and online lives are intimately intertwined, the photos they take are regularly dispersed across social media networks. The interconnectedness of the internet and camera technology presented me with a series of routes with which to explore the online and offline worlds my participants inhabit.

At a glance the photos these young women take of each other are seemingly generic images teenage girls often engage with on social media. However, closer inspection exposes the difficult identity work young Bhutanese refugee women undertake in their experience of growing up in New Zealand. ${ }^{3}$ To make sense of this work I needed a theoretical framework that began with the body. Furthermore, I needed a theoretical approach that allowed a balance between structure and agency. Butler's (2004) concept of gender norms offers this balance. Gender norms are neither rules nor laws, yet they govern social intelligibility, they should be understood as the 'apparatus by which the production and normalization of masculine and feminine take place' (Butler 2004, 42). The resulting photo essay provides an ethnographic account of the gender norms my participants take up, and the shape and texture of the embodied work that surrounds this process.

\section{Bhutanese Youth in Palmerston North}

When I first met the young women, who were to become my participants, I was 
surprised by their confidence and chattiness, both of which challenged assumptions I did not realise I had about refugee women and the vulnerable positions I thought they would occupy (Zotto 2002, 142). The women who participated in this research are a family, comprising of a single mother and her four teenage daughters. They arrived in New Zealand in 2007 and were amongst one of the first Bhutanese families resettled in Palmerston North.

The Bhutanese youth I spoke with throughout my research, were born in Nepal's refugee camps. They have little connection to Bhutan, other than the stories shared with them by their parents and grandparents. As a result, these young people often choose to identify as Nepali instead of Bhutanese. Additionally, these young people look back on their life in Nepal with fond memories. The UNHCR considered camp life in Nepal to be an international example of a wellorganised refugee camp (Hinton 1996, 26). The community established schools and other social groups throughout the camps. As a result, children were able to learn English early in preparation for their resettlement.

Consequently, this group of young people do not fit within academic literature focused on refugee resettlement. They have not come from war-torn circumstances, and thus, do not experience post-traumatic stress disorder, a condition common across other refugee groups of a similar age range. Instead, these young people have spent their lives preparing and awaiting compulsory resettlement in a Western host country (Halley 2014, 61).

Nevertheless, the Bhutanese youth I met throughout my research would often describe their experiences of resettlement in New Zealand as difficult. In Nepal, their local community lived closely together. Housing and domestic space were shared not only with members of one's immediate family but also with the wider community (Halley 2014, 58). One of the benefits of growing up in such close quarters was that these young people lived amongst their peers. Consequently, the most common challenge these young people face in their resettlement is adjusting to a now limited social network. Having moved from Nepal, where their lives were rich with social capital, to a foreign country in which there is only a small circle of people with whom they share commonalities, these young people have had to adapt to having a more limited circle of friendships in their everyday lives.

\section{Visual Routes}

In designing the methodological frameworks of this project, I drew from the photo voice approach, a common methodological tool employed by visual eth- 
nographers (Delgado 2015, 18; Oh 2012, 283; Wang 1999, 185), whereby research participants create a photography portfolio. I supplied each girl with a digital camera each and asked them to create a photo-album that was an expression of their identities. Over the course of my fieldwork, I came to see they were not using their cameras in the way I had expected. They were not taking photos that represented their Bhutanese heritage, rather, the photos were of themselves and friends, with the intention of publishing on social media (Halley 2014, 14). Consequently, I had to adjust my methodologies, to examine both the photo taking process and curation of these photos within their intended digital context. In this way, visual ethnography and digital ethnography intersect; it is therefore important to draw a distinction between these two forms of enquiry. Visual ethnography utilises all forms of media to capture, textual, and creative accounts of ethnographic knowledge. Digital ethnography explores 'how and where user generated content and participatory online practices emerge' (Pink 2013, 132). The photos explored in this paper represent a meeting place between these two methodological routes.

For these young women photo taking is a social event, it is something they do in their leisure time with friends. I found that participating in their practice of photo taking, yielded rich ethnographic data about the gender norms that have come to shape their experiences of resettlement in New Zealand. This meant that I was often included in their photos, and on other occasions they would ask me to be the photographer instead. What interested me most about this process was that photo taking seemed to be the main activity of the day.

\section{The Selfie}

A style of photography the sisters frequently engage with is the selfie. There are three key identifying features of the selfie; it is a photograph that the photographer takes of herself, it is usually taken with a smartphone or webcam, and it is intended to be uploaded to and shared on social media. Iqani (2013) highlights that selfies are both 'predictable in content and conservative in style' but also are 'capable of inducing a photographic experience that can be intensely individual' (p.7). Iqani makes an important observation here, whilst there are key features common within all selfie photographs, the particular socio-cultural norms the photographer is attempting to embody are 'intensely individual' (p.7) and, in this way, locally and culturally relative. Whilst academic research has attempted to unpack the selfie phenomenon (Iqani 2013, 7; Eagar and Dann 2016, 1836; Lim 2016,1774), these photos provide interesting examples of how global texts are appropriated and negotiated at an individual level for the reproduction of localised identities. There is room for further research that explores this practice. 


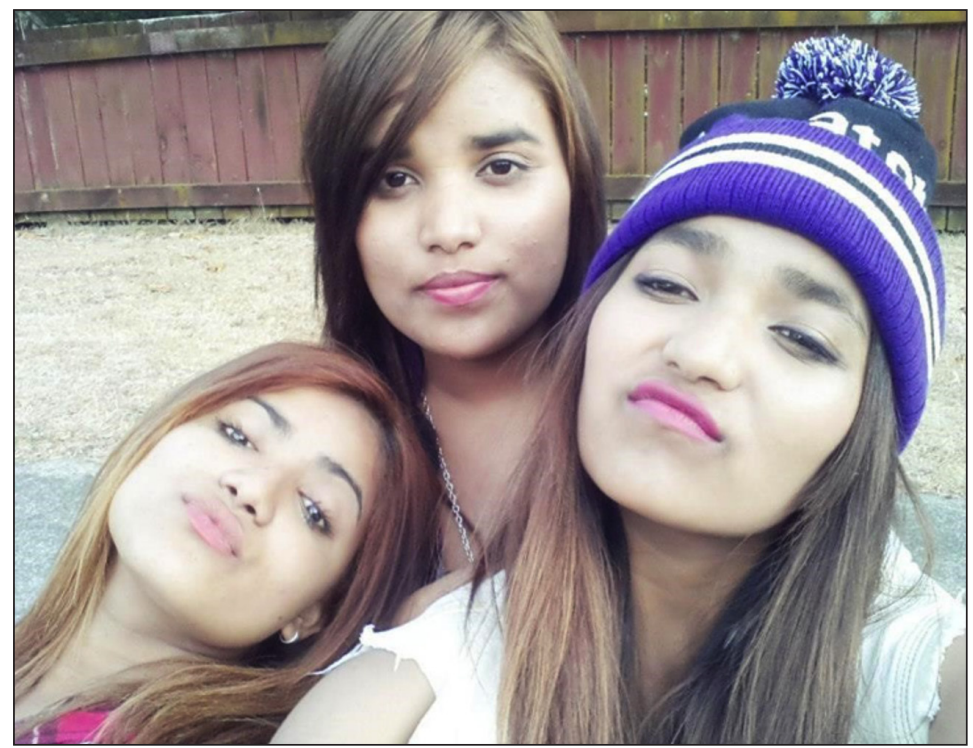

To capture such a wide variety of selfie photographs, this group of young women have become well practised at controlling their facial expressions. Their goal is to capture a shot of themselves that is elusive, instead of directly identifying the participant's mood, the photo should be suggestive and, therefore, subjective or open to interpretation from one's social media community. Capturing such an image requires attention to detail, as my field dairy details below:

Careful preparation has gone into capturing this shot, clothing is thoughtfully selected, negotiated on, and swapped between them. It is decided that they should each wear several layers of the same pink lipstick, to make their lips look plump. The girls huddle together in front of the fence, their heads are bowed closely to ensure that they each fit within the close-up frame of the camera lens. One sister rests her head on the other sister's shoulder. The girl holding the camera angles it high above their heads. I am told this is done deliberately, as a high angle shot elongates the face and highlights the cheek bones. None of the sisters smile as they photograph themselves. Instead they stare directly into the camera lens, they practice a facial expression that is neither a smirk nor pout, but somehow a combination of the two. Getting this balance right takes work. The sisters take photo after photo, giving each other feedback after each shot. 45 minutes later they have reached a consensus on the best photo of the day. 


\section{Facebook and Bhutanese Youth}

These young women put time and thought into taking selfies with the intention of sharing them on Facebook. Facebook is particularly important to Bhutanese youth, as it offers an online environment where they can tap into the rich social networks that were once a part of their daily lives in Nepal. Sharing photographs in this space is a crucial part of maintaining international friendships (Halley 2014, 83). Photos are taken specifically to post them online, allowing their friends fleeting visual access, and insight into their new lives in New Zealand. The photos they share are intended to show their Facebook communities who they are now, and what their life is like in New Zealand. As Sister A states:

We post so many selfie photos because that's the closest thing you can get to hanging out face-to-face. It's the best way for people to understand you on Facebook.

Sharing their photographs on Facebook helps to ease the gap between their online and offline lives. It also provides a visual stimulus whereby their online community can interpret and read the subtle social cues expressed in the carefully choreographed images. Sister A's observation is similar to Van Doorn's (2010) discussions of Facebook interaction. As Van Doorn states, 'instead of deriving social norms from other people's embodied presence; users have to create and interpret the semiotic resources (i.e. text, images, videos) that make up their profiles which effectively constitute a digital infrastructure' (p.585). Both Van Doorn and Sister A are suggesting that users can navigate social norms on Facebook through the images shared within their Facebook communities.

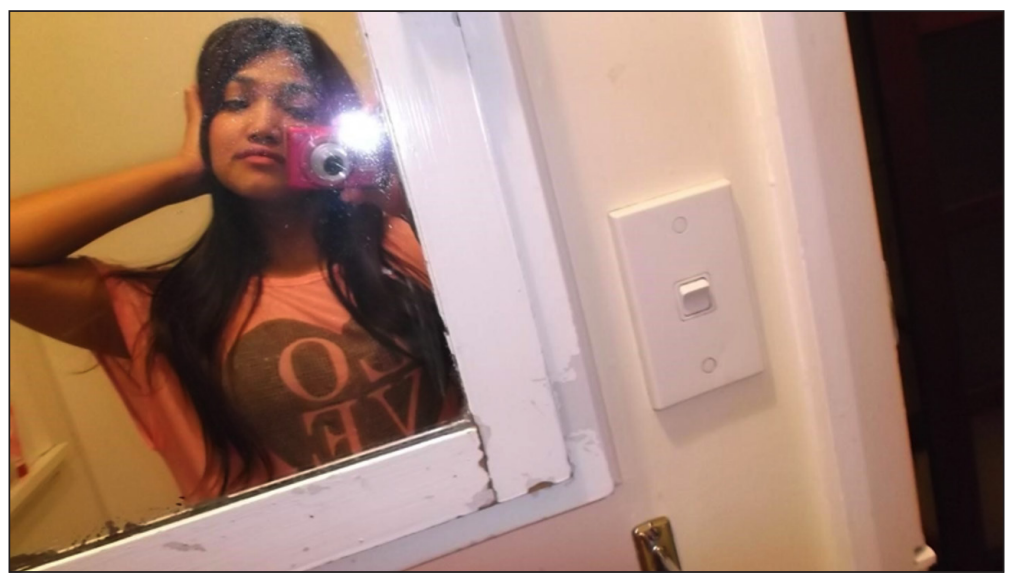


The thing about taking selfies is you can kind of experiment with different versions of yourself. You can be tough looking, or you can be really sweet. Nobody is just one person all the time. So it's a way of playing with different versions of yourself and seeing how you look doing different poses.

For these young people, Facebook is the central social media platform with which to publish their selfie photos. Here social media platforms become interesting spaces to explore the various ways in which visual media converges with digital lives. As the technological landscape that surrounds these socialmedia platforms is frequently changing, this poses new challenges for participant observation. In his 1997 article Studying Up Revisited, Gusterson points out that participant observation works best in a face to face setting. He states, 'participant observation was designed to facilitate the understanding of small, face-to-face societies, such as the Trobriand Islanders, where a stranger could easily be absorbed into the flow of daily life' (p.116). On the contrary, digital communities are often fragmented and dispersed across the globe. Moreover, as social media is more intimately woven within our everyday lives, the times and spaces in which people participate on social media are fluid, personal, and context specific. All of this makes 'face to face' participant observation challenging. Yet, although participant observation is not always possible within this landscape, this has not stopped ethnographic research focused on social media (Bonilla and Rosa 2015, 6; Postill and Pink 2012, 123). The body of this research continues to remind us that each social media community is culturally relative, like other sites of fieldwork, hence we must take a culturally relativistic approach to exploring social media.

While Facebook was created in the United States it has since become a globalised space that does not bear any association with America; it is important to note that non-Americans who become Facebook users are not simply engaging in the process of 'Americanization' (Miller 2011, xii). Rather, Facebook offers a culturally neutral blank space available for different communities to use in various ways. Miller (2011) maintains that there is no 'true' Facebook; instead, Facebook is appropriated by intersecting communities in particular ways.

For Bhutanese youth there is a notable lack of adults, grandparents and community elders present within their Facebook community (Halley 2014, 83). It is primarily a space organised and curated by young people. Indeed, Facebook offers a variety of benefits for Bhutanese youth. It is, first, free to join. Bhutanese young people in Palmerston North are encouraged by community elders to focus on education instead of finding a job. As a result, young people are 
often financially dependent on their parents and have limited disposable income. Young women, in particular, are encouraged to stay at home during the weekends to support their families with domestic labour. Facebook provides a means of socialising with both local and internationally based friends, without needing to leave home. Furthermore, Facebook grants the user an element of control; the participant can choose to reveal certain aspects of their lives to the online world (Zhao, Grasmuck, and Martin 2008, 1823). Consequently, this provides Bhutanese youth with a space to play and experiment with idealised, or fantasised, versions of themselves before a peer audience.

One of the ways I could engage in participant observation within this digital space, was by sharing in the practice of taking selfies and group photos alongside my participants. I took their advice about how to take a good photo, and allowed them to share the photos they took of me on their Facebook pages (Halley 2014, 96). Here, I adopted a comparative approach. I unpacked the distinctions between our ideas about photo taking, what makes a good selfie, and what should be shared online, and this highlighted the complexities of their digital lives.

Having been born in the 1990's, I am only a few years older than my participants. As a result, we shared a lot in common. For instance, they were sitting secondary exams that I had sat not so long ago; they were deciding what they wanted to do with their lives once they finished school, a difficult decision that I had faced just a few years earlier. The young women were also interested in my marital status, as I have only recently married. They frequently asked me questions about what it is like to be 'newly-wed' and about the adult world of dating and finding a partner. We found common ground in this way, as they asked me questions about the choices I had made growing up, and I could relate to the pressures they faced negotiating the border between childhood and adulthood. Contrary to these similarities the differences in the way we engaged with camera-based technology was striking.

My experience of growing up as an adolescent had barely preceeded the rise of mobile phone camera based technology. As a teenager, photo taking required the use of a digital camera, and these were only brought out to record special occasions. Consequently, I was grossly under-skilled at taking 'good' selfies. The sisters had mastered the art of being photogenic; they knew how to angle their faces to generate attractive photos. As well as this, they were confident using their bodies to adopt different poses in front of the camera. On the contrary, I often felt clumsy standing next to them in front of the camera. I was unsure how to use my body to pose, and I often resorted to a typical 'say cheese' type 
smile. The photos we took together would then frame the questions of our focus group discussions. Here, they were often used as an intellectual meeting place, whereby the contradictions between the photographer, the photographed, and me, the viewer, were often made explicit. In particular, the sisters were quick to critique my 'say cheese' smile as the following conversation reveals:

Sister B: 'I think you would be really good at taking selfies, if you just practised it a bit more. Like, sometimes it's ok to do a smile, if that's the look you're going for or something. But all of your photos are smiles. It's good to try something else sometimes. That's how you learn what makes you look good and what doesn't'.

Sister C: 'Yeah like the ones we were taking of you on the swing. Remember... where are they? Here! These ones! Like this photo could have been really sexy if you weren't smiling.

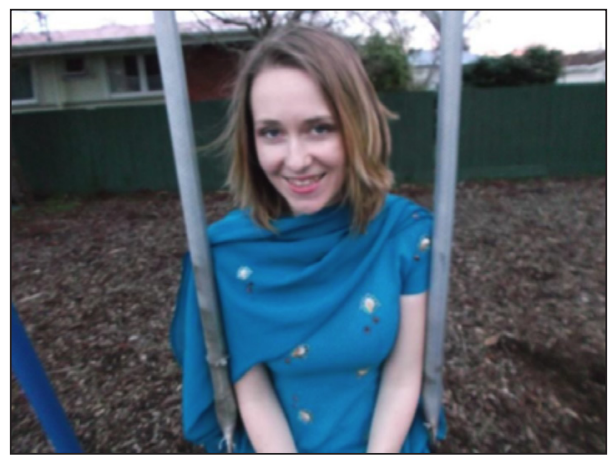

Sister B: 'Like, see the differences here, in these ones between us and you?'

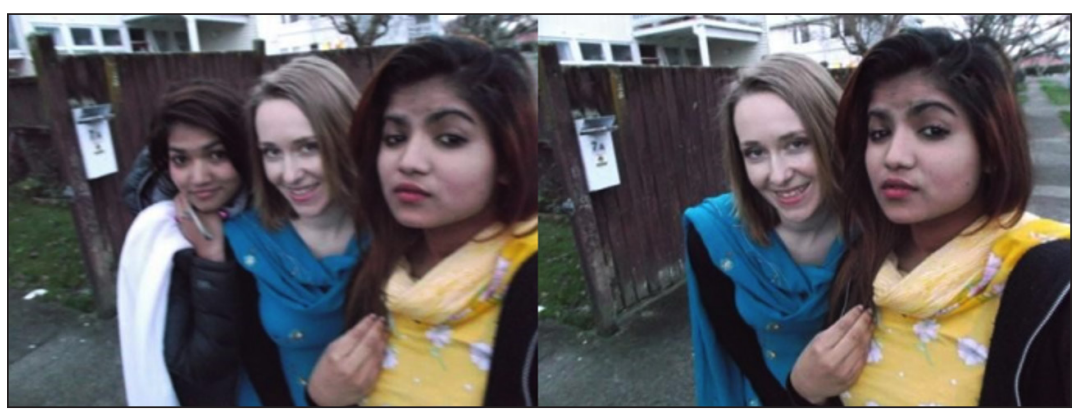


Sister B: 'You're smiling, and we're not. See if you practised doing selfies you would look so pretty and you would be able to take all different kinds of photos'.

The variation between our relationships with the camera served as reminders of the ever-changing technological landscape which transformatively impacts on digital life. Established visual methodologies provided a way of doing participant observation in an online space. Using this method, I gained an embodied understanding of their digital lives in a way that would not have been possible by simply observing their online behaviour. Indeed, digital ethnographers continue to acknowledge the importance of locating digital lives within the context of the offline worlds that they are embedded within (Postill and Pink 2012, 125).

In discussing the intersecting nature of online and offline worlds, Pink (2013) describes how photographic technology is helping digital ethnographers take a culturally relative approach to understanding online practices. She states, 'generally we are starting to see how different photographic technologies and web platforms bring the online and offline together, linking production and dissemination of images in new ways, and moreover, newly situating the photographers socially, digitally and in terms of the places and environments of which they are a part of' (p.134). Consequently, to understand the gender norms these young women draw from in their photo taking practice, we must first dive deeper into the social structures that underpin the Bhutanese community in Palmerston North.

\section{Growing Up In A New Home Country}

The photos we have seen so far, showcase these young women engaging with Western gender norms. It is important to note that Hinduism is the most dominant religious affiliation amongst Bhutanese living in Palmerston North (Halley 2014, 63). In the early stages of their resettlement, traditional Hindu structures of patriarchy and caste ${ }^{4}$ became the organising social dynamics of Bhutanese neighbourhoods (Halley 2014, 63). However, since their arrival, Bhutanese youth have been immersed within a capitalist society, in which consumerism underpins much of daily life. Here they have been exposed to various forms of media that promote Western concepts of gender. Bhutanese youth are now engaging with this media, within both online and offline worlds. Young women, in particular, have demonstrated an active interest in 'trying on' the norms perpetuated within this media, through dressing and styling their bodies (p.130). However, at times, these norms can conflict with traditional Hindu understandings of young women. As a result, Hindu gender norms, which value 
modesty and propriety, are undermined. Instead, the often-sexualised forms of femininity perpetuated within Western consumerist culture have captured the imaginations of Bhutanese youth, as the following discussion reveals.

Author: 'I want to talk about these photos'.
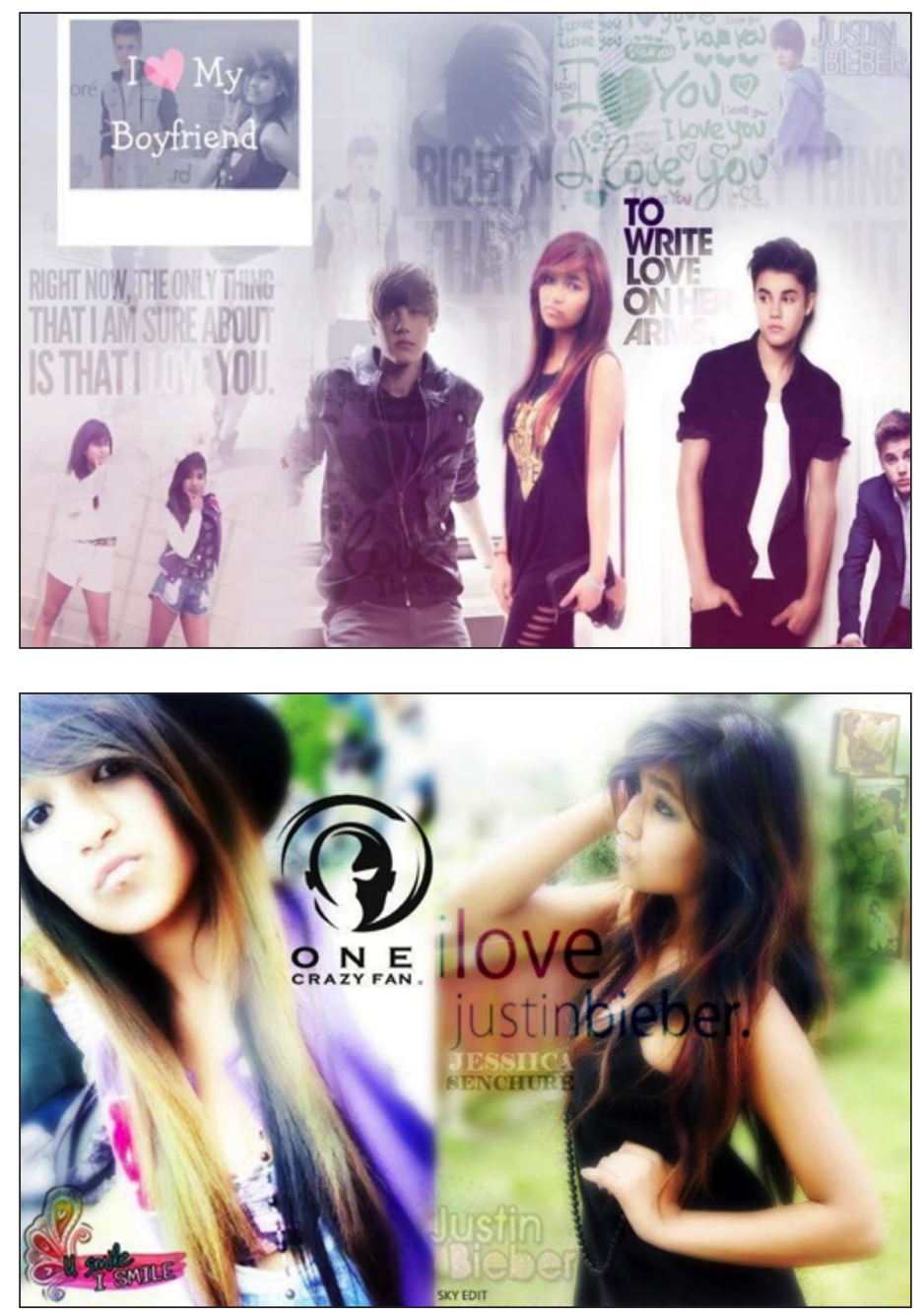

Author: 'I mean, to me that just looks exactly like it came out of a magazine, advertising clothes or make up or something.' 
'Wow! Thanks!'

Author: 'And I see you guys post stuff up like this all the time on Facebook, what's it all about?'

'(Laughs)! I know we do do a lot of these kinds of photos. I don't know. It's cool I guess'.

Author: 'What's cool about it?'

'Umm like you said, it looks like I’m a model in a magazine or something'.

Author: 'Do you get lots of likes for these photos?'

'Yeah, I get heaps'.

Author: 'Why do you think that is?'

'Because it's really cool to be modern and fashionable and stuff. Other Nepali teenagers will look at these photos and think that we're really fashionable and popular and stuff'.

Nairn, Higgins and Sligo (2012) highlight how identity work for young New Zealanders involves the enactment of various texts that structure Western consumerism by stating,

appearance acts as a form of recreation in terms of the images young people choose to look at, how they dress to be looked at... global text - music, fashion, images, film - inform the body work appearance of young people in New Zealand in interesting ways. 'It is how these texts are appropriated and negotiated for the reproduction of localised identity groupings such as race (and gender) that makes the popular significant (Wall, 2007, 27, our emphasis)'. (p.94-95)

For Bhutanese youth, making sense of Western texts involves a practical process of 'trying them on' in front of the camera lens.

'I think a lot of people do it by acting all American on Facebook, like by showing that they like American music and by wearing Western clothes and things because then people think you're really fashionable and pretty. That's why we post pictures like this'. 


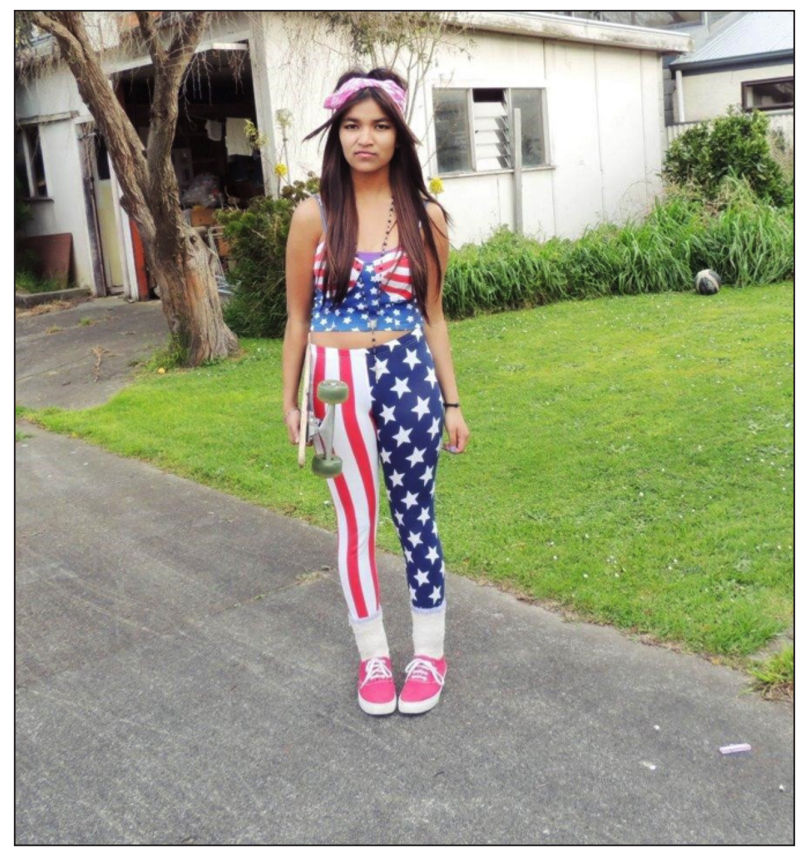

Author: 'So being American on Facebook gets you a lot of likes?'

'Kind of. I think it's more like being modern on Facebook gets you a lot of likes. It's like everybody wants to be fashionable and up to date with the latest fashions and things and, if you are, people will like your comments and they might think that you're rich and pretty and things'.

During my fieldwork, the sisters often photographed each other in the midst of 'laughing', or 'having fun with friends'. The day was spent arranging choreography, yet the photos did not represent this work. Instead, the photos give the illusion of spontaneity, as if the girls were engaged in another activity and, by chance, the photographer captured a photo of them having fun. Ironically, taking a photo that looks spontaneous is a carefully choreographed process that is perfected through repetition. In later conversations the girls identified the global texts that have come to influence this style of photograph:

Author: 'So why do you think posing in this "carefree, hanging out with friend's way" is so crucial to looking popular?' 


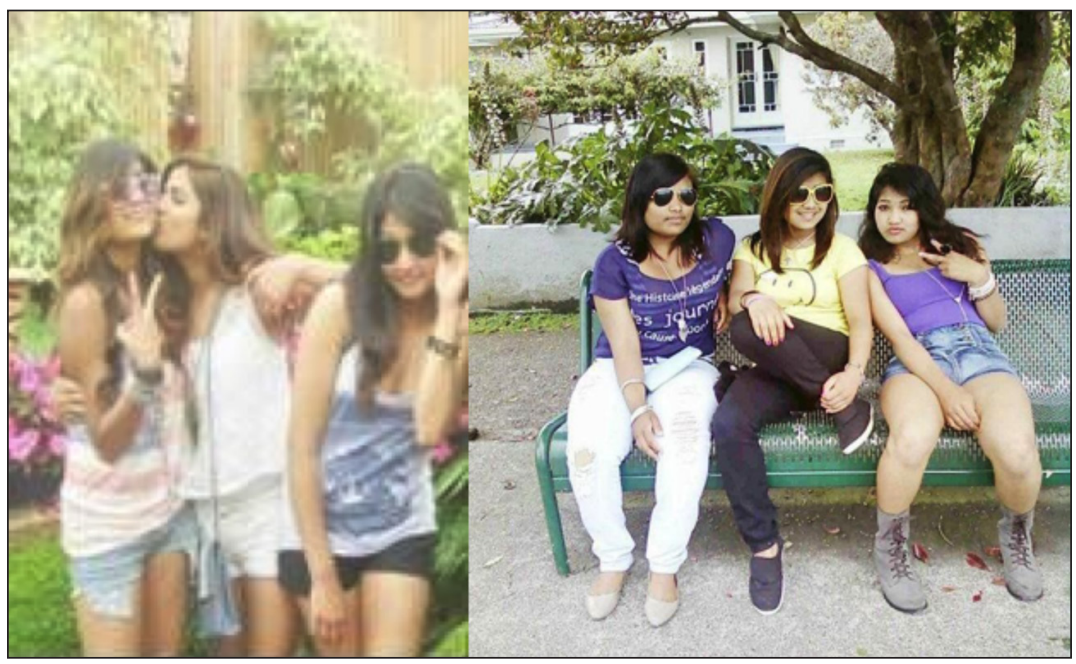

Sister A: 'Hmmm. That's a good question...'

Sister B: 'I think, that it comes from like magazines and TV ads and things. You know, when you see like groups of young girls on TV and in magazine ads, they're all laughing together and hanging out, and maybe that's where these poses and things come from. Because, as girls, we watch that and think "Oh! That's what you're supposed to be like with your friends."'

These young women work hard to gather a variety of 'attractive' shots, each one tapping into, or experimenting with varying concepts of western beauty. The more selfie photos the sisters take, the more they refine their ability to engage with western gender norms stylistically. A crucial aspect of this is achieving a level of subtlety across a range of photos, this requires one to choreograph the body expertly, and some are better at this process than others.

Sister A: 'It's always a different kind of face, depending on how you want to look and how you want others to see you. The most important thing about taking selfies is you don't need to, like, overact, or over smile or something because then it can look really fake.

Sister B: 'Like, it's obvious you're pretending when it's overdone'.

Sister A: 'Yeah!' 


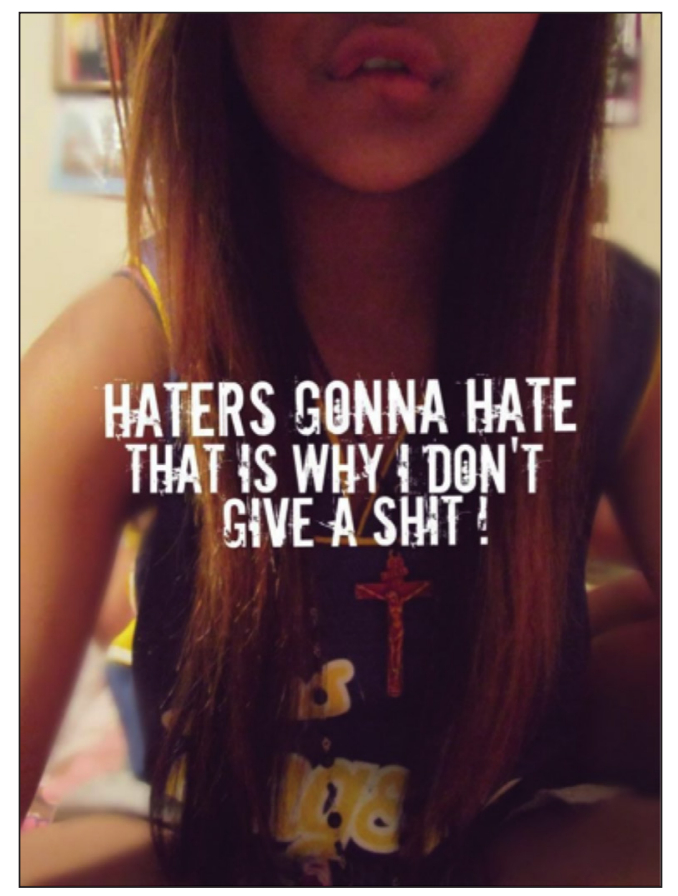

Author: 'So you're saying subtlety is really important when taking selfies?'

Sister A: 'Yeah, I think so!'

Subtlety is a key aspect of this work, for instance, I often noticed the young women grappling over the level of arch applied to their eyebrows. They explained to me that over arching the eyebrow would cause the shot to appear directly sexual and this would be unsophisticated and too obvious. Yet, under arching the brow will result in the appearance of a less symmetrical face. Getting the eyebrow arch balance right takes work, and as a result, this process is intensely repetitive. As the sisters explain;

Sister B: 'It's always important to keep trying. The good thing about it is you can just delete the ones you don't like. So you keep trying, basically, until you get the best ones'.

Author: 'Is that what you were doing here?' 


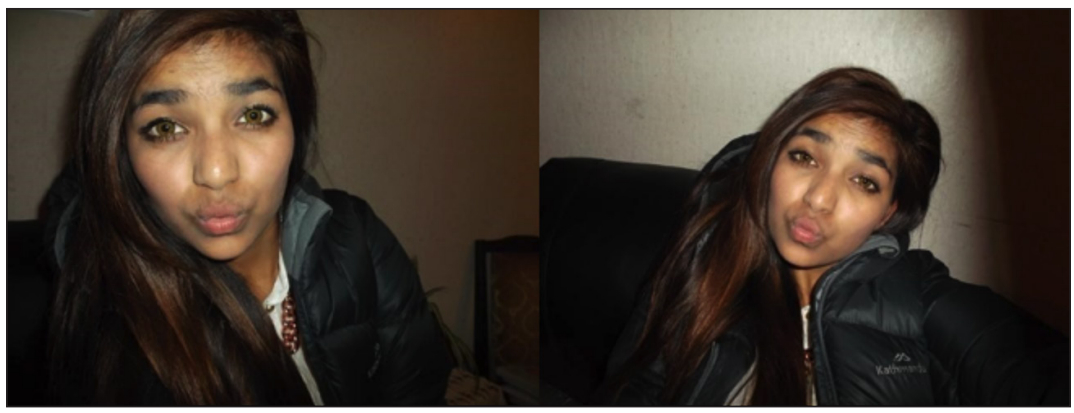

Sister B: 'Yeah, I was, I was trying to take a good duck face selfie for my profile picture. See, I had to take heaps, look'.

Sister B: 'So I think the more selfies you take, the more you get better at it, and you learn the best way to use your face. So, if you took more selfies, you would probably be better at doing other things, instead of just smiling at the camera'.

As they share photos on Facebook, other users add meaning to these images by writing comments or clicking the 'like' button. Here, the girls recognise the intersubjective nature of sharing photos on social media.

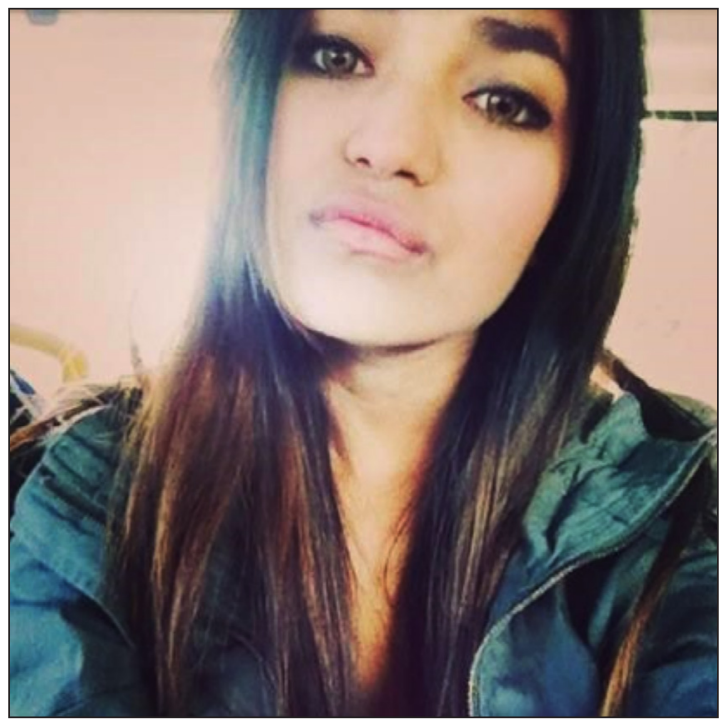


Having a lot of friends in real life and online is good for your Facebook profile. Because if you have a lot of friends, then you can take group photos and everyone on Facebook will think, "Wow! She's 'popular' and everyone will 'like' your pictures on Facebook. Then the more people that 'like' your Facebook pictures, the more popular you will be on Facebook as well!"

\section{Visual Ethnography as a Route to explore Digital Worlds}

As we have seen, the practice of taking selfies is a physically demanding process, whereby the participant learns to choreograph the body in a naturalised fashion. The girls can control their facial expressions and body movement to a precise degree, to capture personal photographs that are 'ambiguous'. Such photographs have a multitude of meanings, as the participant's mood is not directly clear. The various 'likes', comments and postings they receive, adds meaning to these photos. In this way, their bodies are both self-edited and publicly written into being by one's Facebook community. Whilst the act of taking these photos remains a tedious affair for the girls, upon being shared on Facebook they are embedded within a wider digital infrastructure, here they illustrate the identity work that this community of young people are currently undertaking. From this perspective, photographic technologies and online social media forums present new ways for digital ethnographers to think about the concept of embodiment.

Spending time with the camera and these young women made explicit the differences in our relationships with photography. The selfie trend was not a part of my adolescent years and thus I was significantly under skilled at choreographing my body compared to these young women. This research highlights how social media photos provide textual examples of what is meaningful to particular youth cultures. Without visual ethnography, this understanding is often easily missed or unavailable to anthropologists of different generations (Pink 2013, 134). For digital and visual ethnographers this invokes a question regarding utilisation and interrogation of digital technologies within our fieldwork practice. Often, examples of how we might begin to interrogate online worlds or new technological platforms are soon out of date. Thus, tackling this ever-changing technological landscape will demand an adaptive approach and new methodologies from digital ethnographers.

Allowing this research project to be lead primarily by the camera practices my participants were engaging with, transformed their photos into an intellectual meeting space during focus group discussions. Our discussions unpacked the differences between our relationships with photography, as well as dismantling 
the content of particular photos, and situating the girls' lives socially and digitally, regarding the groups and communities they belong to. Here, emerging photographic practices present digital and visual ethnographers with a culturally relative approach to exploring digital lives. As their photographs have paved my understandings of their experiences, I aimed to layer these photos as intellectual routes within the presentation of my ethnographic writing, by captioning each image with transcripts of our discussions.

My fieldwork for this project focused on tracing the visual routes produced by my participant's photographic practices. I found that participating in the practice of photo taking generated rich ethnographic knowledge about these young women's lives, beyond this media. Ultimately, these routes highlighted the identity work young Bhutanese women undertake as they negotiate the process of growing up in a new home country. This identity work is made possible by a series of technologies that interweave their everyday lives, digital photography, social relationships and social media communities. Here we see how the interconnectedness of mobile camera based technology and social media bring the online and offline together to create new ways of being Bhutanese women.

NOTES

1 Jessica Halley's research focuses on the identity work of young adults growing up in New Zealand. Using queer theory, and visual research methodologies, her work explores how discourses of neoliberalism can create both barriers and opportunities for young people.

Email:jmmhalley@gmail.com

2 'Western' is a common term which refers to characteristics, or fashion trends that originate in Western countries, particularly the USA. Quotation marks will be dropped from this term in subsequent use throughout this paper.

3 Throughout this thesis my participants have shared their personal photos, and stories, this means that I cannot protect their identities from anyone who may recognise their faces. However, to further disguise their identities, the sisters shall remain nameless throughout this thesis; I refer to them as sister A, B, C or D simply to distinguish between speakers in a conversation. Consequently, sister A is not a particular participant, but the sister that is speaking first in the conversation.

4 It should be noted that during the early stages of their resettlement in Palmerston North, caste was particularly important to the organisation of this community. 
The Hindu caste system came to influence my participant's experiences of resettlement in complex and intersectional ways. It is beyond the scope of this paper to elaborate further. For more detail refer to Halley $(2014,64)$.

\section{REFERENCES}

Allan, Alexandra. 2005. 'Using Photographic Diaries to Research the Gender and Academic Identities of Young Girls'. In Methodological Issues and Practices in Ethnography, edited by Geoff Troman, Bob Jeffrey and Geoffrey Walford, 19-36. West Yorkshire, United Kingdom: Emerald Group Publishing.

Becker, Howard S. 1974. 'Photography and Sociology'. Studies in the Anthropology of Visual Communication 1(1):3-26.

Bloustien, Gerry, and Sarah Baker. 2003. 'On Not Talking to Strangers: Researching the Micro Worlds of Girls Through Visual Auto-ethnographic Practices'. Social Analysis 47 (3): 64-79.

Bonilla, Yarimar, and Jonathan Rosa. 2015. ‘\# Ferguson: Digital Protest, Hashtag Ethnography, and the Racial Politics of Social Media in the United States. American Ethnologist 42 (1): 4-17.

Byers, Paul. 1964. 'Still Photography in the Systematic Recording and Analysis of Behavioral Data. Human Organization $23: 78-84$.

Delgado, Melvin. 2015. Urban Youth and Photovoice: Visual Ethnography in Action. Oxford University Press: usa.

Del Zotto, Augusta C. 2002. 'Weeping Women, Wringing Hands: How the Mainstream Media Stereotyped Women's Experiences in Kosovo'. Journal of Gender Studies 11(2):141-150.

Eagar, Toni and Stephen Dann. 2016. 'Classifying the Narrated \#Selfie: Genre Typing Human-Branding Activity'. European Journal of Marketing 50 (9/10):18351857.

Halley, Jessica. 2014. Performing Identities on Facebook: Young Bhutanese Women Becoming 'Kiwi'. Masters Dissertation (Social Anthropology), Massey University.

Hinton, Rachel. 1996. 'NGO's as Agents of Change?: The Case of the Bhutanese 
Refugee Programme.' Cambridge Anthropology 19 :24-56.

Hutt, Michael. 1996. 'Ethnic Nationalism, Refugees and Bhutan'. Journal of Refugee Studies 9 (4):397-420.

Iqani, Mehita. 2013. 'Spectacles or Publics? Billboards, Magazine Covers, and 'Selfie's' as Spaces of Appearance'. http://wiser.wits.ac.za/system/files/seminar/ Iqani2013.pdf (accessed October 18, 2016).

Lim, Weng Marc. 2016. 'Understanding the Selfie Phenomenon: Current Insights and Future Research Directions'. European Journal of Marketing 50 (9/10): 1773-1788.

Miller, Daniel. 2011. Tales from Facebook. Cambridge, United Kingdom: Polity Press.

Nairn, Karen Marie, Jane Higgins, and Judith Sligo. 2012. Children of Rogernomics: A Neoliberal Generation Leaves School. Dunedin, New Zealand: Otago University Press.

Oh, Su囚Ann. 2012. 'Photofriend: Creating Visual Ethnography with Refugee Children'. Area $44(3): 382-288$.

Pink, Sarah. 2013. Doing Visual Ethnography 3rd, ed. California: Sage Productions.

Postill, John, and Sarah Pink. 2012. 'Social media ethnography: The digital researcher in a messy web'. Media International Australia 145 (1):123-134.

Schwartz, Dona. 1989. 'Visual Ethnography: Using Photography in Qualitative Research'. Qualitative Sociology 12 (2):119-154.

Sekula, Allan. 1975. 'On the Invention of Photographic Meaning'. Artforum $13(5): 36-45$.

Trafi-Prats, Laura. 2009. 'Destination Raval Sud: A Visual Ethnography on Pedagogy, Aesthetics, and the Spatial Experience of Growing Up Urban'. Studies in Art Education: A Journal of Issues and Research in Art Education 51 (1): 6-20.

Van Doorn, Niels. 2010. 'The Ties That Bind: The Networked Performance of Gender, Sexuality and Friendship on MySpace'. New Media \& Society $12(4): 583-602$. 
Article $\cdot$ Halley

Wang, Caroline C. 1999. 'Photovoice: A Participatory Action Research Strategy Applied to Women's Health'. Journal of Women's Health 8 (2):185-192.

Zhao, Shanyang, Sherri Grasmuck, and Jason Martin. 2008. 'Identity Construction on Facebook: Digital Empowerment in Anchored Relationships'. Computers in Human Behaviour 24 (5):1816-1836. 